\title{
Toward a Shared-Care Model of Relapsing-Remitting Multiple Sclerosis: Role of the Primary Care Practitioner
}

\author{
Jiwon Oh, Marie-Sarah Gagné-Brosseau, Melanie Guenette, Catherine Larochelle, \\ François Lemieux, Suresh Menon, Sarah A. Morrow, Laurence Poliquin-Lasnier, \\ Chantal Roy-Hewitson, Carolina Rush, Anne-Marie Trudelle, Paul S. Giacomini
}

\begin{abstract}
Objective: The objective of this study was to develop a shared-care model to enable primary-care physicians to participate more fully in meeting the complex, multidisciplinary healthcare needs of patients with multiple sclerosis (MS). Design: The design consisted of development of consensus recommendations and a shared-care algorithm. Participants: A working group of 11 Canadian neurologists involved in the management of patients with MS were included in this study. Main message: The clinical management of patients with multiple sclerosis is increasing in complexity as new disease-modifying therapies (DMTs) become available, and ongoing safety monitoring is required. A shared-care model that includes primary care physicians is needed. Primary care physicians can assist in the early detection of MS of individuals presenting with neurological symptoms. Additional key roles for family physicians are health promotion, symptom management, and safety and relapse monitoring of DMT-treated patients. General principles of health promotion include counseling MS patients on maintaining a healthy lifestyle; performing standard screening measures; and identifying and treating comorbidities. Of particular importance are depression and anxiety, which occur in $>20 \%$ of MS patients. Standard work-ups and treatments are needed for common MS-related symptoms, such as fatigue, pain, bladder dysfunction, sexual dysfunction, spasticity, and sleep disorders. Ongoing safety monitoring is required for patients receiving specific DMTs. Multiple sclerosis medications are generally contraindicated during pregnancy, and patients should be counseled to practice effective contraception. Conclusions: Multiple sclerosis is a complex, disabling illness, which, similar to other chronic diseases, requires ongoing multidisciplinary care to meet the evolving needs of patients throughout the clinical course. Family physicians can play an invaluable role in maintaining general health, managing MS-related symptoms and comorbidities, monitoring for treatment-related adverse effects and MS relapses, and coordinating allied health services to ensure continuity of care to meet the complex and evolving needs of MS patients through the disease course.
\end{abstract}

RÉSUMÉ: Élaborer un modèle de soins partagés dans les cas de sclérose en plaques récurrente-rémittente. Objectif: Élaborer un modèle de soins partagés afin de permettre aux médecins de première ligne de mieux répondre aux besoins complexes et multidisciplinaires de patients atteints de la sclérose en plaques (SP). Conception : Recommandations résultant d'un consensus et élaboration d'un algorithme en matière de soins partagés. Participants : Un groupe de travail formé de onze neurologues canadiens impliqués dans la prise en charge de patients atteints de la SP. Message-clé : La prise en charge clinique de patients atteints de la SP est de plus en plus complexe dans la mesure où des médicaments modificateurs de l'évolution de la maladie (MMSP) deviennent accessibles et où un suivi permanent en matière de sécurité est nécessaire. Soulignons aussi qu'un modèle de soins partagés incluant les médecins de première ligne est nécessaire. Ces professionnels peuvent permettre un dépistage plus rapide de la SP chez des individus présentant des symptômes neurologiques. Ils peuvent aussi jouer un rôle de premier plan en matière de promotion de la santé, de soulagement des symptômes et de suivi de patients traités avec des MMSP en ce qui a trait à leur sécurité et à de possibles rechutes. Parmi les principes généraux de promotion de la santé, on peut inclure les suivants : offrir aux patients atteints de la SP des conseils leur permettant de maintenir de saines habitudes de vie ; adopter des mesures de dépistage standards ; identifier et traiter les comorbidités. À cet égard, l'anxiété et la dépression sont d'une importance particulière et sont fréquemment signalées (>20\%) chez les patients atteints de SP. Des démarches d'investigation et des traitements standards sont nécessaires dans le cas des symptômes courants reliés à la SP, par exemple de la fatigue, des douleurs, une dysfonction vésicale, des dysfonctions sexuelles, de la spasticité et des troubles du sommeil. On l'a dit, un suivi permanent s'impose dans le cas de patients bénéficiant d'un traitement spécifique avec des MMSP. Les médicaments associés à la SP sont généralement contre-indiqués durant la grossesse de sorte qu'on devrait conseiller aux patients d'adopter des méthodes de contraception efficaces. Conclusions : La SP est une maladie complexe et invalidante qui, à l'instar d'autres maladies chroniques, exige des soins multidisciplinaires continus afin de répondre, en lien avec un tableau clinique précis, aux besoins en constante évolution des patients. Les médecins de première ligne peuvent jouer un rôle irremplaçable à plusieurs égards : dans le maintien d'une bonne santé ; le suivi et le soulagement des symptômes et des comorbidités reliés à la SP ; le suivi des rechutes et des effets indésirables associés aux traitements. N'oublions pas non plus la coordination des services paramédicaux afin d'assurer, durant l'évolution de la SP, une continuité des soins répondant aux besoins complexes et en constante évolution des patients atteints de cette maladie.

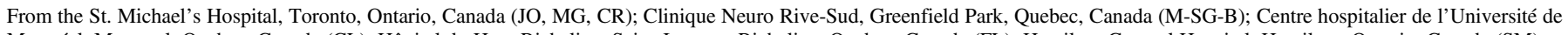

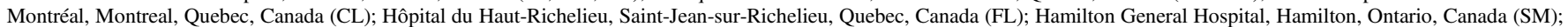

London Health Sciences Centre, London, Ontario, Canada (SAM); Hôpital de Gatineau, Gatineau, Quebec, Canada (LP-L); The Ottawa Hospital, Ottawa, Ontario, Canada (CR-H);

Montreal Neurological Hospital, Montreal, Quebec, Canada (A-MT, PSG).

Received June 6, 2017. Final Revisions Submitted December 1, 2017. Date of Acceptance December 12, 2017.

Correspondence to: Jiwon Oh, Neurology, St. Michael's Hospital, 30 Bond Street, Toronto, ON, M5B 1W8, Canada. Email: ohjiw@smh.ca 
Keywords: Multiple sclerosis, Primary care, Shared care model, Symptom management

doi:10.1017/cjn.2018.7

Can J Neurol Sci. 2018; 45: 304-312

\section{INTRODUCTION}

Multiple sclerosis (MS) is the most common disabling neurological condition affecting young adults. ${ }^{1}$ Prevalence estimates in Canada range from 177 to 267 cases per $100,000 .^{2,3}$ The female-tomale ratio is approximately $3: 1 .^{2}$ The mean age at symptom onset is 32 years, although diagnosis is typically delayed for 3-5 years. ${ }^{4}$

The clinical signs and symptoms of MS are the result of autoimmune dysregulation, in which activated $\mathrm{T}$ and $\mathrm{B}$ cells cross the blood-brain barrier into the central nervous system (CNS) and release inflammatory mediators that result in demyelination and axonal loss. ${ }^{5}$ Known risk factors for the development of MS include the HLA-DRB*1501 allele, which is most common in individuals of northern European descent; lower sun exposure and/or lower serum vitamin D levels; cigarette smoking; and exposure to the Epstein-Barr virus (EBV) or other herpes viruses during adolescence. ${ }^{6}$

The clinical hallmarks of relapsing-remitting MS (RRMS) are relapses, defined as onset or exacerbations of neurological signs/ symptoms persisting for at least 24 hours, not attributable to elevated body temperature (due to fever, infection, heat exposure), and not better explained by an alternative diagnosis. Typically, clinical symptoms related to relapses evolve over days to weeks, followed by varying degrees of recovery. About $85 \%$ of patients present with RRMS, in which neurological exacerbations alternate with periods of remission; recovery may be complete or partial. In untreated patients with RRMS, the frequency of relapses diminishes over time, but a majority of patients will eventually develop secondary-progressive MS (SPMS), ${ }^{7}$ in which there is ongoing neurodegeneration with few or no relapses. In contemporary cohorts, there is evidence that earlier diagnosis and initiation and maintenance of disease-modifying therapies (DMTs) may reduce disability in the long term and the proportion of RRMS patients reaching SPMS, ${ }^{8,9}$ but this is controversial because of the inherent biases of observational cohorts. About $10 \%-15 \%$ of patients present with primary-progressive MS (PPMS), where there is progressive neurological worsening from onset.

Over the past two decades, the treatment paradigm for people living with RRMS has changed markedly, partly owing to everincreasing DMT options, but also owing to improved understanding of the pathophysiology of MS. Currently, 11 DMTs are available in Canada to target different aspects of the dysfunctional immune response seen in RRMS (Table 1). In Canada, treatment initiation is largely restricted to neurologists specialized in MS care at one of the country's $32 \mathrm{MS}$ clinics (see Appendix 1). ${ }^{10}$ Long-term treatment is generally recommended throughout the relapsing-remitting phase of the disease, along with periodic safety monitoring.

Primary care physicians (PCP) can play a central role in the ongoing management of MS. Although no shared-care model that includes PCPs has yet been developed for MS, given the increasing complexity of chronic management of MS patients, it is apparent that such a model would greatly benefit patients. The following is a proposal outlining how PCPs can more fully participate in the care path to meet the complex, multidisciplinary healthcare needs of their MS patients, particularly in the evolving modern era of MS treatment.

\section{EARLy Detection}

Multiple sclerosis can affect many areas of the CNS and can present clinically in myriad ways. Common symptoms related to an MS relapse can include a history of sensory disturbances (e.g., asymmetrical numbness or dysesthesia/hyperesthesia), neurologic pain (e.g., burning sensation, trigeminal neuralgia), motor symptoms (weakness, spasticity), visual symptoms (e.g., monocular visual impairment with pain, loss of color vision, disc pallor, diplopia), fatigue, heat sensitivity, imbalance, and poor coordination. Other common symptoms include bladder urgency or retention, bowel dysfunction, sexual dysfunction, and neurocognitive symptoms (depression, anxiety, cognitive impairment).

The differential diagnosis can be challenging as a number of other conditions can mimic MS. A diagnosis of MS is less likely if there is a sudden, rapid onset of symptoms ( $<1$ hour to maximal deficit); later onset (after age 50 years); transient, migrating symptoms; peripheral neuropathy; fever; diffuse, whole-body pain; arthralgias; skin rash; or prominent cortical features (e.g., seizures). When there are atypical clinical features present, in the appropriate clinical context, some conditions that may need to be taken into consideration include infections (e.g., human immunodeficiency virus, Lyme disease, syphilis), systemic inflammatory diseases (e.g., Behçet syndrome, sarcoidosis, Sjögren syndrome, systemic lupus erythematosus), vascular disease (e.g., migraine, vasculitis), nutritional deficiencies (e.g., folate, vitamin $B_{12}$, vitamin $E$ ), psychiatric conditions (e.g., anxiety, conversion disorder), genetic conditions (mitochondrial disorders, spastic paraparesis), ${ }^{11}$ and other inflammatory diseases of the CNS (neuromyelitis optica and solitary sclerosis). ${ }^{12,13}$ Routine blood tests and other investigations may be useful to rule out MS mimics (Table 2). ${ }^{14}$

\section{DiagnOSIS}

The clinical hallmark that characterizes MS is multiple neurological events separated in space and time. ${ }^{15}$ It is important to keep in mind that MS is a clinical diagnosis, requiring symptoms or signs typically associated with demyelinating lesions, although MRI of the brain and spine is now routinely employed to make the diagnosis. ${ }^{16,17}$ The "dissemination in space" criterion for MS is met by objective evidence of lesions in two or more areas of the brain and/or spinal cord on the clinical exam (polysymptomatic) or based on lesions in suggestive areas of the neuroaxis on an MRI. For the RRMS "dissemination in time" criterion, careful history-taking is essential to identify two discrete episodes of neurological worsening separated by at least 30 days, ${ }^{15}$ and to exclude other causes, such as infection or fever. Relapses may be reported by the examination. The "dissemination in time" criterion can also be met by the presence of new lesions on an MRI scan with reference to a baseline scan, irrespective of the timing of the baseline scan, or the simultaneous presence of gadoliniumenhancing and non-enhancing lesions on the same scan (as long as 
Table 1: Disease-modifying therapies approved for use in relapsing-remitting multiple sclerosis (MS)

\begin{tabular}{|c|c|c|}
\hline Agent & Brand & Noteworthy side effects and suggested management \\
\hline \multicolumn{3}{|l|}{ Injection } \\
\hline Interferon $\beta$-1a & $\begin{array}{l}\text { Avonex } \\
\text { Plegridy }\end{array}$ & $\begin{array}{l}\text { Transaminitis: repeat labs, consult neurologist, discontinue if }>3-5 \text { times } \\
\text { upper limit of normal and symptomatic, rule out other causes } \\
\text { Flu-like reactions: NSAIDS, Tylenol } \\
\text { Skin reactions: cold compresses, NSAIDS }\end{array}$ \\
\hline Interferon $\beta-1 \mathrm{a}$ & Rebif & \\
\hline Interferon $\beta-1 \mathrm{~b}$ & Betaseron; Extavia & \\
\hline Glatiramer acetate & Copaxone; Generics & Skin lipoatrophy with chronic use: rotate injection sites appropriately \\
\hline Daclizumab & Zynbryta & $\begin{array}{l}\text { Transminitis/hepatitis: repeat labs, consult neurologist, discontinue if }>3-5 \text { times } \\
\text { upper limit of normal and symptomatic, rule out other causes } \\
\text { Skin reactions: topical/oral steroids if needed, discontinue medication (if severe), } \\
\text { consult dermatologist }\end{array}$ \\
\hline \multicolumn{3}{|l|}{ Oral } \\
\hline Teriflunomide & Aubagio & $\begin{array}{l}\text { Reversible alopecia: typically resolves with continuous treatment } \\
\text { Transaminitis: repeat labs, consult neurologist, discontinue if }>3-5 \text { times } \\
\text { upper limit of normal and symptomatic, rule out other causes }\end{array}$ \\
\hline Dimethyl fumarate & Tecfidera & $\begin{array}{l}\text { Gastrointestinal symptoms: ensure that the patient is not taking medication } \\
\text { on an empty stomach } \\
\text { Flushing: ASA } \\
\text { PML: discontinue medication, immediate referral to ER/neurologist for MRI, } \\
\text { and further management }\end{array}$ \\
\hline Fingolimod & Gilenya & $\begin{array}{l}\text { Herpes zoster: antiviral, pain control } \\
\text { Herpes encephalitis (rare): antiviral, immediate referral to ER/neurologist } \\
\text { PML (rare): discontinue medication, immediate referral to ER/neurologist for MRI, } \\
\text { and further management } \\
\text { Macular edema: discontinue medication and referral to neurologist } \\
\text { Cryptococcal meningitis (rare): antifungal, discontinue medication, immediate } \\
\text { referral to ER/neurologist for MRI, and further management }\end{array}$ \\
\hline \multicolumn{3}{|c|}{ Infusion (at infusion center) } \\
\hline Natalizumab & Tysabri & $\begin{array}{l}\text { PML: discontinue medication, immediate referral to ER/neurologist for MRI, } \\
\text { and further management }\end{array}$ \\
\hline Alemtuzumab & Lemtrada & $\begin{array}{l}\text { Autoimmune thyroiditis: immediate referral to neurologist and endocrinologist } \\
\text { for further management } \\
\text { Immune thrombocytopenic purpura: immediate referral to ER/neurologist and } \\
\text { hematologist for further management } \\
\text { Glomerulonephritis: immediate referral to ER/neurologist and hematologist for } \\
\text { further management }\end{array}$ \\
\hline Ocrelizumab & Ocrevus & $\begin{array}{l}\text { Breast malignancy (rare): follow standard screening guidelines, immediate } \\
\text { referral to oncologist and neurologist if identified }\end{array}$ \\
\hline
\end{tabular}

ASA = acetyl-salicylic acid; ER = emergency room; NSAIDS = non-steroidal anti-inflammatory drugs; PML = progressive multi-

focal leukoencephalopathy.

the gadolinium-enhancing lesion is not symptomatic). In PPMS, dissemination in time is characterized by a minimum of 1 year of progressive neurological symptoms. ${ }^{18}$

Table 2: Routine blood tests to rule out multiple sclerosis (MS) mimics

\begin{tabular}{l|l}
\hline Test & MS mimic \\
\hline Antinuclear antibody titer & $\begin{array}{c}\text { Rheumatologic disease; systemic } \\
\text { lupus erythematosus }\end{array}$ \\
\hline Complete blood count & Infection; inflammation; neoplasm \\
\hline Erythrocyte sedimentation rate & Infection; inflammation \\
\hline Thyroid-stimulating hormone & Hypothyroidism \\
\hline Vitamin $\mathrm{B}_{12}$ & Vitamin $\mathrm{B}_{12}$ deficiency \\
\hline
\end{tabular}

Adapted from Saguil et al. ${ }^{11}$
Patients who present with a typical demyelinating event (e.g., one relapse) but who do not meet the clinical or radiological criteria of dissemination in space and time are categorized as having a clinically isolated syndrome (CIS). Clinically isolated syndrome with MRI lesions is highly predictive of the later development of MS. Also noteworthy is radiologically isolated syndrome (RIS), which is the incidental finding of MS-like lesions on MRI; ${ }^{19}$ an estimated onethird of RIS patients will have an initial clinical event over the next 5 years and will accordingly be diagnosed with CIS or MS. ${ }^{20}$

MRI findings suggestive of MS include periventricular, infratentorial, juxtacortical, and spinal cord lesions in the CNS. A gadolinium contrast agent, if available, is useful to identify new inflammatory lesions resulting from blood-brain barrier permeability.

\section{Role OF THE PCP IN MS Diagnosis}

The temporary, intermittent nature of early MS symptoms can result in considerable diagnostic delays. Recent revisions to the 
diagnostic criteria (the McDonald criteria ${ }^{15,18}$ ) have enabled earlier MS diagnosis, ${ }^{21}$ although it remains to be determined whether this will result in improved long-term outcomes compared with historical cohorts.

Primary care physicians can play an important role in the early detection of demyelinating disease. The annual incidence of MS in Canada ranges from 5 to 11 cases per $100,000,{ }^{3,22}$ suggesting that an average family physician will encounter one new MS case every 1-2 years.

In patients with symptoms or signs suggestive of a first relapse of MS, an MRI of the brain with gadolinium should be ordered if possible, and the patient has no known contraindications to receiving a contrast agent. MRI of the spinal cord should be ordered if the MRI of the brain is non-diagnostic, or if symptomatology is referable to this region. ${ }^{17,23,24}$ To expedite the scan, the requisition should describe the patient's suspicious signs and symptoms (e.g., monocular vision loss with pain) rather than simply stating "suspected MS." The MRI should generally take place within 3 months of presentation, and more urgently if the suspicion of MS is high. Patients with lesions on MRI suggestive of MS should be referred to an MS specialty center to make the diagnosis. A reasonable expectation is that the MS specialist will assess the patient within 6 months of MRI. However, if the PCP is concerned about aggressive MS (frequent relapses, significant disability early in disease), it may be necessary to request a more urgent appointment. It is prudent not to confirm a diagnosis of MS until the patient has undergone a full neurological examination and work-up.

If the PCP foresees a significant delay with the MRI, an urgent referral to a community neurologist may be appropriate to expedite the scan. In addition, if an MS clinic appointment will be delayed $>6$ months, the MRI reveals white-matter lesions of uncertain etiology, or the patient is unable to travel to a provincial MS clinic, an urgent referral to a community neurologist may be appropriate, who can counsel the patient and initiate a DMT (if necessary) while awaiting an MS clinic appointment.

Referral documentation provided to the neurologist should include relevant findings from the patient's history and physical examination (including recent changes in health status), patientreported symptoms (type, frequency, severity), laboratory results, MRI images, and the MRI report, if obtained. A medication history, including recent treatments for suspected MS-related symptoms, is also needed. It is useful to ensure that a patient's vaccination schedule is up-to-date as MS medications can alter the immune response, which may be associated with an increased risk of infections and an impaired ability to mount an immune response. Of particular importance are live attenuated vaccines (e.g., measles, mumps, chickenpox), as the safety of administering these vaccines is unknown once a DMT has been initiated.

\section{Role of the PCP in Managing Patients Diagnosed with RRMS}

There are three principal roles for PCPs in the management of patients diagnosed with MS: health maintenance and promotion, MS symptom management, and DMT safety monitoring. Of particular importance are general health maintenance and promotion. In patients with a chronic illness such as MS, clinicians tend to view health status through the prism of that condition, which may result in neglecting routine preventative measures, and misattributing symptoms to their MS.

\section{Health Maintenance and Promotion}

Patients should be counseled about maintaining a healthy lifestyle (smoking cessation, regular exercise, diet), and will require the usual screening measures (routine blood work, vascular risk factor screening, Pap smear, colonoscopy, and so on). Recommendations on a variety of topics related to MS are available on a number of reputable websites (www.mssociety.ca, www.msbrainhealth.org) for both patients and healthcare practitioners. $^{25}$

Individuals with MS are at risk of obesity, partly owing to MS fatigue and mobility difficulties. A recent survey reported that a high proportion of individuals with MS were overweight $(22.5 \%)$ or obese $(19.4 \%)$, with obesity associated with increased risks of diabetes (odds ratio [OR] 4.8) and hypertension (OR 4.5), ${ }^{26}$ as is seen in the non-MS population. Obesity may partly account for the increasing incidence of diabetes, hypertension, hyperlipidemia, and ischemic heart disease that has been reported among Canadians with MS. ${ }^{27}$ Counseling individuals about smoking cessation is especially relevant: active and passive smoking have been reported to be risk factors for the development of $\mathrm{MS},{ }^{28}$ and continuing to smoke may accelerate disease progression. ${ }^{6}$ Comorbid illness in MS patients is associated with an increased risk of hospitalizations and mortality, and a significantly poorer quality of life. ${ }^{29-31}$

Vitamin D supplementation is now recognized as an important aspect of health maintenance in MS, as there is emerging evidence that having an adequate vitamin D level has beneficial effects in MS patients. Many MS patients are vitamin D deficient, and doses up to $4000 \mathrm{IU}$ daily are generally recommended. As part of their routine care, PCPs should thus recommend vitamin D supplementation in newly diagnosed patients, or in those who are not yet on supplementation, and can monitor levels to ensure adequate supplementation. ${ }^{16,32}$

Primary care physicians can also provide counseling about pregnancy planning. Multiple sclerosis does not appear to affect a woman's fertility. ${ }^{33}$ There is a genetic susceptibility to MS in offspring. The absolute risk of MS in the offspring of a patient with MS is approximately $2 \%-4 \% .{ }^{34}$ Pregnancy does not have a negative impact on the long-term prognosis of MS. ${ }^{35}$ For the vast majority of patients, having a known diagnosis of MS does not affect decisions regarding labor, delivery method, use of epidural anesthetic, or use of routine medications during labor and delivery, and in the postpartum period. Thus, patients should make this decision based on the obstetrician's recommendations. However, in cases in which patients have severe disability, special consideration may need to be given around labor and delivery to minimize harm to the mother and fetus, and the obstetrician and neurologist should both be involved in this decision. ${ }^{36}$

Disease-modifying treatments are not recommended for use in patients who are pregnant, trying to conceive, or breastfeeding. ${ }^{35}$ The effects of DMTs on pregnancy and lactation have not been well studied, but there is evidence that some of these agents have the potential to cause fetal harm. If a patient with MS is contemplating pregnancy, the PCP should recommend that she discuss this in detail with her MS specialist for the most current recommendations on DMT use peri-pregnancy. As most DMTs should not be used during the conception period, it is recommended that patients try to adequately plan pregnancy, and utilize methods to conceive without an excessive delay to minimize time off DMT. If conception does not occur within 
6-12 months, fertility counseling should be sought to minimize time off DMT, and risk of relapse.

Generally, all DMT-treated female MS patients should be counseled to practice effective contraception. Although most DMTs are not known to affect oral contraceptives, they may not be optimal contraceptives as some DMTs (teriflunomide) may affect these agents' pharmacokinetics. ${ }^{37}$ Long-acting reversible contraception (e.g., subdermal rod or an intrauterine device) may be preferable. ${ }^{35}$ It is important to advise patients that, in most cases, it is not sufficient to stop their DMT when pregnancy occurs. Some DMTs have long half-lives and drug levels may be detectable for months or years after discontinuation. Women who wish to become pregnant should be counseled to continue using their DMT and practise effective contraception until they have consulted with their neurologist. The clinic will schedule discontinuation of the patient's DMT to enable an adequate washout period before pregnancy. In patients who are taking teriflunomide (Aubagio), an accelerated elimination procedure is available, and should be performed for patients planning to conceive, or in the case of unexpected pregnancy.

Health maintenance includes the need for PCPs to manage other medical conditions as comorbidities are common in the MS population. The prevalence of irritable bowel syndrome and chronic lung disease is reported to be more than $10 \%{ }^{38}$ Respiratory dysfunction resulting from infection is the most common reason for admission to neuro-intensive care and is associated with a fourfold increased risk of mortality compared with non-MS patients. ${ }^{39}$ There is also some evidence of an increased risk of other autoimmune diseases, notably psoriasis, thyroid disease, and uveitis. ${ }^{40}$

Of particular importance in primary care is the diagnosis and management of depression and anxiety, both of which occur in $>20 \%$ of patients. ${ }^{41}$ Indeed, one study found that patients and healthcare professionals view family practitioners as the healthcare provider best suited to play a central role in meeting MS patients' mental healthcare needs. ${ }^{42}$ Psychological and pharmacological therapies have been shown to be effective in MS patients with depression. ${ }^{43}$ Patients can also be counseled on the benefits of exercise, mindfulness, yoga, and other stress management techniques that may enable them to cope better with chronic illness.

\section{MS Symptom Management (Table 3)}

Second, PCPs can play an important role in managing MS-related symptoms (Table 3). Common problems that PCPs may encounter in MS patients include fatigue, pain syndromes, bladder dysfunction, sexual dysfunction, spasticity, and sleep disorder. For symptoms such as fatigue, pain, and sleep disorders that are also commonly seen in the general population, PCPs should perform standard work-ups for these symptoms. If there is another identifiable cause of the symptom, it should generally be managed as it would be in the non-MS population.

One of the most common MS-related symptoms is fatigue, which is reported to be severe and disabling in up to $70 \%$ of patients. ${ }^{44}$ A multimodal approach is needed to manage factors that may contribute to MS fatigue, such as excluding other medical conditions (e.g., thyroid dysfunction, depression, sleep apnea), pain, muscle spasms or nocturia that can disrupt sleep, or medication-related sideeffects, which can include both fatigue or insomnia (e.g., psychostimulants, fampridine, some DMTs, anti-spasmodics) ${ }^{45}$

An estimated $29 \%-86 \%$ of MS patients experience disabling pain symptoms. ${ }^{46}$ Neuropathic pain, such as Lhermitte's sign (electrical sensation down the spine on neck flexion), pain in the extremities, and trigeminal neuralgia are common. Treatment options include antiepileptic agents (e.g., pregabalin, gabapentin, carbamazepine) or antidepressants (amitriptyline, duloxetine); cannabinoids may also be used ${ }^{47,48}$ although evidence for their efficacy is limited.

Bladder dysfunction in MS is most commonly due to detrusor overactivity with symptoms such as urinary frequency, urgency, and nocturia. ${ }^{49}$ Patients may be referred to a urologist for a full work-up, including urinalysis, uroflowmetry, measurement of post-void residual (PVR) volume, and assessment of renal function. First-line treatment is with an anti-muscarinic agent; botulinum toxin A injections may also be useful. In the case of anti-muscarinic agents, PCPs should evaluate PVR as these drugs can worsen urinary retention. Alternatively, patients with MS may have difficulties emptying the bladder, which can result in urinary retention and frequent urinary tract infections (UTIs). Cholinergic agents (e.g., bethanechol) and $\alpha$-1-agonists (e.g., tamsulosin) can be used in some cases, and self-catheterization may eventually be necessary. In MS patients with symptoms of urinary retention (incomplete

Table 3: Multiple sclerosis (MS) symptom management in primary care

\begin{tabular}{|c|c|c|}
\hline MS-related symptom & Management & Referral \\
\hline Neurogenic pain & Pregabalin, gabapentin, carbamazepine, amitriptyline, duloxetine, cannabinoids & Neurologist, physiatrist, or pain specialist \\
\hline Bladder (frequency, nocturia) & $\begin{array}{l}\text { Oxybutynin, timed voids, lifestyle modification (avoid excessive fluid intake } \\
\text { before bed), botulinum A }\end{array}$ & $\begin{array}{l}\text { Urologist (urinalysis, uroflowmetry, post-void residual } \\
\text { volume, renal function) }\end{array}$ \\
\hline Bladder (retention, frequent UTIs) & Bethanechol, tamsulosin, self-catheterization & Refer if post-void residual volume $>100 \mathrm{cc}$ \\
\hline Sexual dysfunction & $\begin{array}{l}\text { Viagra/Cialis for men, assess whether it is due to other issues (fatigue, pain, } \\
\text { mood, urinary, spasticity) and refer accordingly }\end{array}$ & Psychologist, counselor, or therapist \\
\hline Bowel (diarrhea, constipation) & $\begin{array}{l}\text { Diet, avoid dehydration, fiber supplements, docusate sodium, sennosides, } \\
\text { lactulose }\end{array}$ & $\begin{array}{l}\text { MS clinic or gastroenterologist if chronic, intractable } \\
\text { symptoms }\end{array}$ \\
\hline Spasticity & Baclofen, tizanidine, and gabapentin, stretching exercises & Physiotherapist or occupational therapist \\
\hline Depression/anxiety & Antidepressants, cognitive-behavioral therapy & Psychiatrist if severe symptoms or suicidal ideation \\
\hline Cognitive dysfunction & $\begin{array}{l}\text { Assess for other causes (fatigue, depression) if occurring early in the disease. } \\
\text { Treat fatigue, depression if present }\end{array}$ & $\begin{array}{l}\text { MS clinic if patient having difficulty at work or impaired } \\
\text { function in daily life owing to cognitive difficulties }\end{array}$ \\
\hline Sleep disorder & $\begin{array}{l}\text { Rule out primary sleep disorder (e.g., sleep apnea, other parasomnia); } \\
\text { recommend sleep hygiene measures }\end{array}$ & Sleep lab if primary sleep disorder is suspected \\
\hline
\end{tabular}


emptying, excessive straining to empty bladder, frequent UTIs), PCPs should perform PVR, if possible, and consider a referral to a urologist if the PVR is $>100 \mathrm{cc}$.

Sexual dysfunction (e.g., diminished libido, erectile dysfunction, anorgasmia) is common in MS but is often under recognized and inadequately managed. A multimodal approach is generally needed to manage MS symptoms that may affect sexual functioning (e.g., fatigue, incontinence, spasticity), and address psychosocial issues (e.g., depression, cognitive impairment). ${ }^{50}$ Primary care physicians can play an important role in initiating a discussion of sexual functioning, and to refer patients to specialist medical services, psychologists, and therapists, as needed.

Spasticity symptoms range from mild muscle stiffness to sudden or sustained muscle contractions, and may be associated with back pain, arthralgia, and myalgia (most commonly of the legs). Patients should be counseled to engage in daily stretching or other exercises. First-line medications include baclofen, tizanidine, and gabapentin. ${ }^{51}$ If no improvement is seen, diazepam or dantrolene may provide some benefit. There is some evidence supporting the use of cannabinoids for spasticity. ${ }^{52}$ Botox injections can be considered for focal spasticity and/or refractory cases. A referral to a physical/ occupational therapist or physiatrist should be considered.

Sleep disorders often arise secondary to MS symptoms, such as MS fatigue, neuropathic pain, nocturia, spasticity or limb movement disorders, or as a symptom of depression and anxiety. Patients will benefit from symptom management and counseling about sleep hygiene measures, such as avoidance of caffeinated beverages, restricting the consumption of liquids in the evening, and avoidance of stimulating activities (exercise, computer/tablet use) around bedtime. If a primary sleep disorder (obstructive sleep apnea or another parasomnia) is suspected, a referral for a sleep study should be made.

It should be noted that when prescribing symptomatic medications in DMT-treated patients, there are few pharmacological interactions that are noteworthy. Pharmacists are a valuable community resource and can provide information on potential drug-drug interactions.

Finally, PCPs can play a role in monitoring for relapses in patients with RRMS. Sub-acute onset of new neurological symptoms or worsening of pre-existing neurological symptoms that last for at least 24 hours and typically progress over many days warrant further investigation. In this situation, PCPs can first ensure that patients do not have concomitant infections that can exacerbate neurological symptoms and cause "pseudo-relapses," and order appropriate tests as needed. When an infection has been ruled out, PCPs may be able to facilitate a visit to the neurologist's office, or local emergency room for patients to be assessed and treated with steroids, if warranted. In some settings, the PCP may even be comfortable prescribing high-dose oral steroids (prednisone $1250 \mathrm{mg}$ daily for $3-5$ days), ${ }^{53,54}$ but patients should be warned of side effects of shortterm, high-dose steroids, which can include insomnia, hypertension, gastrointestinal symptoms, hyperglycemia, and avascular necrosis.

\section{Safety and Efficacy Monitoring in DMT-Treated MS Patients}

Disease-modifying treatments are associated with a number of acute and chronic adverse effects that require ongoing monitoring. Monitoring requirements differ for each DMT, but necessary investigations can include periodic blood tests (e.g., liver enzymes, complete blood count, lymphocyte count, thyroid function), urine tests, ophthalmic examinations, and MRIs. The prescribing neurologist generally performs safety monitoring, with additional assistance from the drug manufacturers' patient support programs. On occasion, neurologists may ask PCPs to include specific tests or procedures in the next primary-care visit and to forward the information to the MS clinic.

If a routine test obtained in primary care raises a concern that the result is out of keeping with what is expected with the specific DMT the patient is prescribed, the PCP should contact the consulting neurologist for advice and to schedule an appointment at the MS clinic. Although a comprehensive list of side effects of all DMTs is beyond the scope of this manuscript, common and noteworthy side effects and suggested management are listed in Table 3. Progressive multifocal leukoencephalopathy (PML) is a rare but serious potential adverse event that can occur with a number of DMTs, but has been seen most commonly with natalizumab. Progressive multifocal leukoencephalopathy is an opportunistic infection of the brain and can present in a myriad of ways, which can include weakness, visual or sensory disturbance, confusion, imbalance, and incoordination. Symptom onset can be subtle, but is generally progressive over days to weeks, and can often be difficult to distinguish from an MS-related relapse. If the concern for PML is present, PCPs should immediately send patients to an urgent care facility and notify the treating neurologist, who can arrange for appropriate investigations and management, which can include lumbar puncture, MRI, and discontinuing the culprit medication.

In addition to playing a role in safety monitoring of DMTs, PCPs may also facilitate patient care by monitoring for breakthrough MS disease activity. Although treatment algorithms can differ among MS neurologists, and continue to change as a result of the rapidly evolving therapeutic landscape, patients are generally monitored using both clinical and MRI measures. When a patient who is either untreated or who has been on a particular DMT for an adequate amount of time demonstrates evidence of breakthrough clinical relapses or significant MRI disease activity (usually more than 3-5 new lesions per year), the treating neurologist will typically initiate or change DMT. ${ }^{55-59}$ The PCP can play an important role in this setting by recommending that the patient be seen more urgently by his/her treatment neurologist. Furthermore, PCPs can inquire about medication compliance, and encourage adherence or recommend that patients be assessed by his/her neurologist more urgently to consider other options if medication adherence is an issue. Medication persistence is one of the most important factors that determine a DMT's efficacy, and PCPs can play an important role in this regard. ${ }^{60}$

\section{Toward a Shared-Care Model of MS}

The treatment landscape of MS is dynamic, and continues to increase in complexity as a number of novel treatments are expected to be approved for use in the near future.

Multiple sclerosis is a complex, disabling illness, which like other chronic diseases requires ongoing multidisciplinary care to meet the evolving needs of patients throughout the clinical course.

Although the diagnosis and treatment of MS are the responsibility of a specialized MS center or community neurologist, there is an urgent need for PCPs to participate actively in the care of MS patients. Primary care physicians play an essential role in providing continuity of care, educating patients about community resources (Appendix 2), and coordinating the provision of allied healthcare services.

In the shared-care model proposed above, there are a number of specific areas in which PCPs may contribute significantly in the care 
of people living with MS. Primary care physicians are an important first-contact in the early detection of symptoms suggestive of MS. Following the diagnosis of MS and possible initiation of a DMT, PCPs can provide support with ongoing health maintenance, manage comorbidities and MS-related symptoms, and can also assist in safety monitoring with specific DMTs. Primary care physicians are also vital in providing patients with ongoing advice and encouragement, and are central to the coordination of allied healthcare services, such as physiatry, physiotherapy, occupational therapy, nutritional counseling, psychiatry, and psychological services.

In the modern era of MS treatment, what is becoming evident is that it is only through the combined efforts of PCPs, neurologists, and allied healthcare teams that the evolving and complex needs of patients will be met during the life-long course of MS. Ultimately, the goal of this team approach is to improve the lives of people living with MS.

\section{ACKNOWLEDGMENTS}

All authors have reviewed the final version of this manuscript and have agreed with the conclusions. Authors received funding from Sanofi Genzyme for participation at a roundtable meeting to discuss the development of the contents of this paper. The sponsor provided no editorial input during the development of the manuscript. The authors acknowledge the editorial assistance of Steven Manners of Communications Lansdowne, whose help was made possible through funding from Sanofi Genzyme.

\section{Disclosures}

JO reports grants from Sanofi Genzyme, during the study period, grants from MS Society of Canada, grants from National MS Society, grants from Biogen Idec, grants from Sanofi Genzyme, personal fees from EMD Serono, personal fees from Sanofi Genzyme, personal fees from Biogen-Idec, personal fees from Teva, personal fees from Novartis, and personal fees from Roche, outside the submitted work.

M-SG-B reports grants from Sanofi Genzyme, during the study period.

CL reports personal fees from Teva, personal fees from Novartis, personal fees from Biogen, personal fees from Sanofi Genzyme, and from Merck Serono, outside the submitted work.

FL reports grants from Sanofi Genzyme, during the study period.

SM reports grants from Sanofi Genzyme, during the study period, fellowship funding from Multiple Sclerosis International Federation, grants from Consortium of MS Centers, grants from Western Pacific endMS Regional Research and Training Centre, grants from European Committee for the Treatment and Research in Multiple Sclerosis, personal fees from Sanofi Genzyme, personal fees from Roche, personal fees from Novartis, personal fees from Biogen, and personal fees from EMD Serono, outside the submitted work.

SAM reports grants from Sanofi Genzyme, during the study period, personal fees from Biogen, personal fees from Sanofi Genzyme, personal fees from EMD Serono, personal fees from Novartis, personal fees from Roche outside the submitted work. SAM also worked as the site principal investigator in an industry-sponsored clinical trial with Novartis, Sanofi Genzyme, and Roche, outside the submitted work.

LP-L reports grants from Sanofi Genzyme, during the study period, personal fees from Biogen, personal fees from EMD Serono, and personal fees from Sanofi Genzyme, outside the submitted work.
CR-H reports grants from Sanofi Genzyme, during the study period, personal fees from EMD Serono, personal fees from Novartis, personal fees from Biogen, personal fees from Sanofi Genzyme, and personal fees from Roche, outside the submitted work.

CR reports grants from Sanofi Genzyme, during the study period, personal fees from Bayer Healthcare, personal fees from Biogen Idec, personal fees from Roche, personal fees from EMD Serono, personal fees from MedDay, personal fees from Novartis, personal fees from Sanofi-Aventis, and personal fees from Teva, outside the submitted work.

A-MT reports grants from Sanofi Genzyme, during the study period, personal fees from Biogen-Idec, personal fees from EMD Serono, personal fees from Roche, personal fees from Novartis, personal fees from Sanofi Genzyme, and personal fees from Teva, outside the submitted work.

PSG reports grants from Sanofi Genzyme, during the study period, grants from Biogen, grants from Teva, grants from Alexion, grants from Bayer HealthCare, grants from Biogen, grants from Elan, grants from EMD Serono, grants from GlaxoSmithKline, grants from MedDay, grants from Novartis, grants from Ono, grants from Roche, grants from Sanofi-Aventis, grants from Teva, personal fees from NeuroRx, personal fees from Allergan, personal fees from Bayer HealthCare, personal fees from Biogen, personal fees from EMD Serono, personal fees from Sanofi Genzyme, personal fees from Mrez, personal fees from Novartis, personal fees from Roche, and from Teva, outside the submitted work.

MG has nothing to disclose.

\section{REFERENCES}

1. Leary SM, Porter B, Thompson AJ. Multiple sclerosis: diagnosis and the management of acute relapses. Postgrad Med J. 2005;81 (955):302-8.

2. Kingwell E, Zhu F, Marrie RA, et al. High incidence and increasing prevalence of multiple sclerosis in British Columbia, Canada: findings from over two decades (1991-2010). J Neurol. 2015; 262(10):2352-63.

3. Marrie RA, Fisk JD, Stadnyk KJ, et al. The incidence and prevalence of multiple sclerosis in Nova Scotia, Canada. Can J Neurol Sci. 2013;40(6):824-31.

4. Public Health Agency of Canada. 2014 Mapping connections: an understanding of neurological conditions in Canada. Available at: http://www.phac-aspc.gc.ca/publicat/cd-mc/mc-ec/index-eng.php. Accessed December 1, 2017.

5. Trapp BD, Peterson J, Ransohoff RM, Rudick R, Mork S, Bo L. Axonal transection in the lesions of multiple sclerosis. N Engl $\mathrm{J}$ Med. 1998;338(5):278-85.

6. McKay KA, Jahanfar S, Duggan T, Tkachuk S, Tremlett H. Factors associated with onset, relapses or progression in multiple sclerosis: a systematic review. Neurotoxicology. 2017;61:189-212.

7. Trojano M, Paolicelli D, Bellacosa A, Cataldo S. The transition from relapsing-remitting MS to irreversible disability: clinical evaluation. Neurol Sci. 2003;24(Suppl 5):S268-70.

8. Ford C, Goodman AD, Johnson $\mathrm{K}$, et al. Continuous long-term immunomodulatory therapy in relapsing multiple sclerosis: results from the 15-year analysis of the US prospective open-label study of glatiramer acetate. Mult Scler. 2010;16(3):342-50.

9. Kappos L, Kuhle J, Multanen J, et al. Factors influencing long-term outcomes in relapsing-remitting multiple sclerosis: PRISMS-15. J Neurol Neurosurg Psychiatry. 2015;86(11):1202-7.

10. Marriott JJ, Mamdani M, Saposnik G, Gomes T, Manno M, O'Connor PW. Multiple sclerosis disease-modifying therapy prescribing patterns in Ontario. Can J Neurol Sci. 2013;40(1):67-72.

11. Saguil A, Kane S, Farnell E. Multiple sclerosis: a primary care perspective. Am Fam Physician. 2014;90(9):644-52. 
12. Lattanzi S, Logullo F, Di Bella P, Silvestrini M, Provinciali L. Multiple sclerosis, solitary sclerosis or something else? Mult Scler. 2014;20(14):1819-24.

13. Oh J, Levy M. Neuromyelitis optica: an antibody-mediated disorder of the central nervous system. Neurol Res Int. 2012;2012:460825.

14. Brownlee WJ, Hardy TA, Fazekas F, Miller DH. Diagnosis of multiple sclerosis: progress and challenges. Lancet. 2017;389(10076):1336-46.

15. McDonald WI, Compston A, Edan G, et al. Recommended diagnostic criteria for multiple sclerosis: guidelines from the International Panel on the diagnosis of multiple sclerosis. Ann Neurol. 2001;50(1):121-7.

16. MS Brain Health - Time Matters. Available at msbrainhealth.org. Accessed December 7, 2017.

17. Traboulsee A, Letourneau-Guillon L, Freedman MS, et al. Canadian Expert Panel recommendations for MRI use in MS diagnosis and monitoring. Can J Neurol Sci. 2015;42(3):159-67.

18. Polman $\mathrm{CH}$, Reingold SC, Banwell B, et al. Diagnostic criteria for multiple sclerosis: 2010 revisions to the McDonald criteria. Ann Neurol. 2011;69(2):292-302.

19. Okuda DT, Mowry EM, Beheshtian A, et al. Incidental MRI anomalies suggestive of multiple sclerosis: the radiologically isolated syndrome. Neurology. 2009;72(9):800-5.

20. Okuda DT, Siva A, Kantarci O, et al. Radiologically isolated syndrome: 5-year risk for an initial clinical event. PLoS One. 2014;9(3):e90509.

21. Rovira A, Swanton J, Tintore M, et al. A single, early magnetic resonance imaging study in the diagnosis of multiple sclerosis. Arch Neurol. 2009;66(5):587-92.

22. Marrie RA, Yu N, Blanchard J, Leung S, Elliott L. The rising prevalence and changing age distribution of multiple sclerosis in Manitoba. Neurology. 2010;74(6):465-71.

23. Traboulsee $\mathrm{A}, \mathrm{Li} \mathrm{D}$. Addressing concerns regarding the use of gadolinium in a standardized MRI protocol for the diagnosis and follow-up of multiple sclerosis. AJNR Am J Neuroradiol. 2016;37(12):E82-3.

24. Traboulsee A, Simon JH, Stone L, et al. Revised recommendations of the consortium of MS Centers Task Force for a standardized MRI protocol and clinical guidelines for the diagnosis and follow-up of multiple sclerosis. AJNR Am J Neuroradiol. 2016;37(3):394-401.

25. Motl RW. Benefits, safety, and prescription of exercise in persons with multiple sclerosis. Expert Rev Neurother. 2014;14(12):1429-36.

26. Marck CH, Neate SL, Taylor KL, Weiland TJ, Jelinek GA. Prevalence of comorbidities, overweight and obesity in an international sample of people with multiple sclerosis and associations with modifiable lifestyle factors. PLoS One. 2016;11(2):e0148573.

27. Marrie RA, Fisk J, Tremlett H, et al. Differing trends in the incidence of vascular comorbidity in MS and the general population. Neurol Clin Pract. 2016;6(2):120-8.

28. Zhang $\mathrm{P}$, Wang $\mathrm{R}, \mathrm{Li} \mathrm{Z}$, et al. The risk of smoking on multiple sclerosis: a meta-analysis based on 20,626 cases from casecontrol and cohort studies. PeerJ. 2016;4:e1797.

29. Berrigan LI, Fisk JD, Patten SB, et al. Health-related quality of life in multiple sclerosis: direct and indirect effects of comorbidity. Neurology. 2016;86(15):1417-24.

30. Marrie RA, Elliott L, Marriott J, et al. Effect of comorbidity on mortality in multiple sclerosis. Neurology. 2015;85(3):240-7.

31. Marrie RA, Elliott L, Marriott J, Cossoy M, Tennakoon A, Yu N. Comorbidity increases the risk of hospitalizations in multiple sclerosis. Neurology. 2015;84(4):350-8.

32. Multiple Sclerosis Society of Canada. Available at: mssociety.ca; 2017.

33. Roux T, Courtillot C, Debs R, Touraine P, Lubetzki C, Papeix C. Fecundity in women with multiple sclerosis: an observational mono-centric study. J Neurol. 2015;262(4):957-60.

34. O'Gorman C, Lin R, Stankovich J, Broadley SA. Modelling genetic susceptibility to multiple sclerosis with family data. Neuroepidemiology. 2013;40(1):1-12.

35. Coyle PK. Management of women with multiple sclerosis through pregnancy and after childbirth. Ther Adv Neurol Disord. 2016; 9(3):198-210.

36. Coyle PK. Multiple sclerosis is pregnancy. Continuum. 2014; 20(1 Neurology of Pregnancy):42-59.

37. PRODUCT MONOGRAPH PrAUBAGIO®. Teriflunomide tablets $14 \mathrm{mg}$. Immunomodulator Agent. Sanofi Genzyme, a division of sanofi-aventis Canada Inc. Mississauga, ON, January 25, 2017.
38. Marrie RA, Reider N, Stuve O, et al. The incidence and prevalence of comorbid gastrointestinal, musculoskeletal, ocular, pulmonary, and renal disorders in multiple sclerosis: a systematic review. Mult Scler. 2015;21(3):332-41.

39. Karamyan A, Dunser MW, Wiebe DJ, et al. Critical illness in patients with multiple sclerosis: a matched case-control study. PLoS One. 2016;11(5):e0155795.

40. Marrie RA, Reider N, Cohen J, et al. A systematic review of the incidence and prevalence of autoimmune disease in multiple sclerosis. Mult Scler. 2015;21(3):282-93.

41. Marrie RA, Reingold S, Cohen J, et al. The incidence and prevalence of psychiatric disorders in multiple sclerosis: a systematic review. Mult Scler. 2015;21(3):305-17.

42. Methley A, Campbell S, Cheraghi-Sohi S, Chew-Graham C. Meeting the mental health needs of people with multiple sclerosis: a qualitative study of patients and professionals. Disabil Rehabil. 2017;39(11):1097-105.

43. Fiest KM, Walker JR, Bernstein CN, et al. Systematic review and metaanalysis of interventions for depression and anxiety in persons with multiple sclerosis. Mult Scler Relat Disord. 2016;5:12-26.

44. Khan N, Smith MT. Multiple sclerosis-induced neuropathic pain: pharmacological management and pathophysiological insights from rodent EAE models. Inflammopharmacology. 2014;22(1): $1-22$.

45. Hadjimichael O, Vollmer T, Oleen-Burkey M, North American Research Committee on Multiple Sclerosis. Fatigue characteristics in multiple sclerosis: the North American Research Committee on Multiple Sclerosis (NARCOMS) survey. Health Qual Life Outcomes. 2008;6:100.

46. Tur C. Fatigue management in multiple sclerosis. Curr Treat Options Neurol. 2016;18(6):26

47. Solaro C, Messmer Uccelli M. Pharmacological management of pain in patients with multiple sclerosis. Drugs. 2010;70(10):1245-54.

48. Turcotte D, Doupe M, Torabi M, et al. Nabilone as an adjunctive to gabapentin for multiple sclerosis-induced neuropathic pain: a randomized controlled trial. Pain Med. 2015;16(1):149-59.

49. Phe V, Chartier-Kastler E, Panicker JN. Management of neurogenic bladder in patients with multiple sclerosis. Nat Rev Urol. 2016; 13(5):275-88

50. Lew-Starowicz M, Gianotten WL. Sexual dysfunction in patients with multiple sclerosis. Handb Clin Neurol. 2015;130:357-70.

51. Otero-Romero S, Sastre-Garriga J, Comi G, et al. Pharmacological management of spasticity in multiple sclerosis: systematic review and consensus paper. Mult Scler. 2016;22(11):1386-96.

52. Whiting PF, Wolff RF, Deshpande S, et al. Cannabinoids for medical use: a systematic review and meta-analysis. JAMA. 2015; 313(24):2456-73

53. American Academy of Neurology. CONTINUUM: Lifelong Learning in Neurology. Am Academy Neurol. 2010;16(5, Multiple Sclerosis): 1-313.

54. Lattanzi S, Cagnetti C, Danni M, Provinciali L, Silvestrini M. Oral and intravenous steroids for multiple sclerosis relapse: a systematic review and meta-analysis. J Neurol. 2017;264(8): 1697-1704.

55. Freedman MS, Selchen D, Arnold DL, et al. Treatment optimization in MS: Canadian MS Working Group updated recommendations. Can J Neurol Sci. 2013;40(3):307-23.

56. Romeo M, Martinelli V, Rodegher M, et al. Validation of 1-year predictive score of long-term response to interferon-beta in everyday clinical practice multiple sclerosis patients. Eur J Neurol. 2015;22(6):973-80

57. Suthiphosuwan S, Kim D, Bharatha A, Oh J. Imaging markers for monitoring disease activity in multiple sclerosis. Curr Treat Options Neurol. 2017;19(5):18

58. Lattanzi S, Danni M, Cerqua R, Taffi R, Provinciali L, Silvestrini M. Prediction of disability progression in fingolimod-treated patients. J Neurol Sci. 2015;358(1-2):432-4.

59. Río J, Rovira A, Tintoré M, et al. Evaluating the response to glatiramer acetate in relapsing-remitting multiple sclerosis (RRMS) patients. Mult Scler. 2014;20(12):1602-8.

60. Lattanzi S, Danni M, Taffi R, et al. Persistence to oral diseasemodifying therapies in multiple sclerosis patients. J Neuro. 2017;264(11):2325-9. 


\section{APPENDIX 1}

MS clinics in Canada

British Columbia

- Burnaby Hospital Burnaby, BC

- UBC Hospital Vancouver, BC

- Kelowna General Hospital Kelowna, BC

- Royal Jubilee Hospital Victoria, BC

- Prince George Regional Hospital Prince George, BC

\section{Alberta}

- Foothills Hospital Calgary, AB

- Red Deer Regional Hospital Red Deer, AB

- Edmonton Clinic Edmonton $\mathrm{AB}$

\section{Saskatchewan}

- Saskatoon City Hospital Saskatoon, SK

\section{Manitoba}

- Health Sciences Centre Winnipeg, MB

\section{Ontario}

- St. Michael's Hospital Toronto, ON

- The Hospital for Sick Children Toronto, ON

- Sunnybrook Health Sciences Centre Toronto, ON

- Hamilton Health Sciences Hamilton, ON

- Thunder Bay MS Clinic Thunder Bay, ON

- Kingston General Hospital Kingston, ON

- London Health Sciences Centre London, ON

- Ottawa Hospital General Campus Ottawa, ON

- Children's Hospital of Eastern Ontario Ottawa, ON

\section{Quebec}

- Montreal Neurological Institute Montreal, QC

- Hôpital Notre-Dame-CHUM Montréal, QC

- Clinique de SP de Hôpital Maisonneuve-Rosemont Montréal, QC

- Hôpital Sacré-Cœur Montréal, QC
- Montreal Children's Hospital, Neuropediatric clinic, Glen site Montréal QC

- Clinique de SP (Nord de l'Île de Montréal/Laval) Saint-Laurent, QC

- Neuro Rive-Sud MS Clinic Greenfield Park, QC

- Clinique Neuro-Outaouais Gatineau, QC

- Centre hospitalier régional de Trois-Rivières Trois-Rivières, QC

- Clinique de maladies neuromusculaires et de sclérose en plaques IRDPQ Quebec City, QC

- Centre de Rèadaptation en Déficience Physique Charny, QC

- CHUS-Site Fleurimont Fleurimont, QC

- Clinique Accès-Santé Rouyn-Noranda, QC

- Clinique de SP du CSSS de Rivière-du-Loup Rivière-du-Loup, QC

- Clinique de SP du Centre hospitalier régional de Lanaudière (CHRDL)

Saint-Charles Borromée, QC

- Clinique SEP CSSS du Sud de Lanaudière (Centre hospitalier Pierre-Le-Gardeur)

Terrebonne (secteur Lachenaie), QC

- Clinique neurologique de l'hôpital régional de St-Jérôme St-Jérôme, QC

- Hôpital St-Jean-sur-Richelieu St-Jean-sur Richelieu, QC

- Clinique neuro spécialisée de Hôpital Chicoutimi Chicoutimi, QC

\section{New Brunswick}

- Saint John Regional Hospital Saint John, NB

- The Moncton Hospital Moncton, NB

\section{Nova Scotia}

- Dalhousie MS Research Unit Halifax, NS

- Cape Breton Regional Hospital Sydney, NS

\section{Newfoundland-Labrador}

- OPD Neurology Clinic St. John's NL

\section{APPENDIX 2}

Available resources for MS patients in Canada

- MS Society of Canada: https://mssociety.ca/ Includes information on local patient support groups

- US National MS Society www.nationalmssociety.org/

- US National Library of Medicine: www.nlm.nih.gov/ medlineplus/multiplesclerosis.html

- www.msbrainhealth.org 